\title{
Burden of blood transmitted infections in substance users admitted for inpatient treatment in Singapore and the associated factors
}

\author{
Rochelle Melina Kinson ${ }^{1}$, MB BCh BAO, MMed, Song $\underline{G u O}^{2}$, MBBS, PhD, Yi Min $\underline{W a n}^{3}$, MB BCh BAO, MMed,
} Victoria Manning ${ }^{2,4}$, MSc, PhD, Hui Chin Teoh${ }^{2}$, BSocSci, Kim Eng Wong², MBBS, MRCPsych

\begin{abstract}
INTRODUCTION There is a paucity of local data on the prevalence of blood transmitted infections (BTIs), such as hepatitis $B$, hepatitis $C$ and human immunodeficiency virus (HIV) infections, among illicit drug users. This study aimed to examine the prevalence of BTIs among substance-dependent inpatients and identify the factors associated with BTIs. METHODS We conducted a retrospective case note analysis of 170 inpatients who had a history of substance dependence and were seen at the National Addictions Management Service, Singapore, between 1 June 2009 and 31 May 2010.

RESULTS The majority of the 170 inpatients were male (88.2\%) and Chinese (58.2\%). The mean age of the patients was 43.1 years, and the main drug of abuse was opioids (86.5\%). BTIs were found in $70(41.2 \%)$ inpatients; the prevalence of hepatitis B, hepatitis $C$ and HIV infections was 3.7\%, 39.6\% and $0 \%$, respectively. Lifetime intravenous drug use, but not needle-sharing, was more common among inpatients who were positive for BTIs $(p<0.01)$. Logistic regression analysis showed that lifetime intravenous drug use (OR 4.3, 95\% Cl 1.7-10.8, p < 0.01) was the only significant predictor of BTI. CONCLUSION $41.2 \%$ of the substance users seeking help were positive for at least one BTI. Lifetime intravenous drug users were found to be more than four times more likely to have a BTI. Early detection and prevention is essential to improve prognosis.
\end{abstract}

Keywords: hepatitis B virus, hepatitis C virus, human immunodeficiency virus, intravenous drug use, substance use disorder

\section{INTRODUCTION}

Drug abuse has been a problem in Singapore for decades, albeit to a much lesser degree when compared to the rest of the world. Injecting substance users are at high risk for infection with several blood-borne pathogens, including hepatitis B virus (HBV), hepatitis $\mathrm{C}$ virus (HCV) and human immunodeficiency virus (HIV). Transmission is primarily parenteral, through the sharing of needles, syringes and other paraphernalia. ${ }^{(1-3)}$ Viral hepatitis can present in a myriad of forms - from a mild self-limiting viral illness to fulminant hepatitis, hepatocellular carcinoma and death. Early detection and treatment confers a better prognosis, limiting end organ damage and the spread of the virus. According to the World Drug Report in 2011, the global prevalence of HBV, $\mathrm{HCV}$ and HIV among injecting drug users is $22.0 \%, 50.3 \%$ and $17.9 \%$, respectively. ${ }^{(4)}$ Other reports from the United States of America show that among persons using intravenous (IV) drugs, the prevalence of $\mathrm{HBV}$ ranges from $65 \%-71 \%$, while that of $\mathrm{HCV}$ and HIV ranges from $27 \%-90 \%$ and $1 \%-20 \%$, respectively. ${ }^{(5-12)}$

Singapore currently subscribes to a zero tolerance policy, and hence does not practice harm reduction. This approach is not unique to Singapore; a 2010 global report on HIV showed that 66 countries had no oral substitution therapy programmes and 55 countries had no needle-exchange programmes. ${ }^{(13)}$ Statistics from the Central Narcotics Bureau, Singapore, show a steady increase in the number of arrests of substance abusers from the year 2005; 793 arrests were documented in 2005, while 3,326 arrests were documented in 2011. ${ }^{(14)}$ The majority (93\%) of the substance abusers arrested abused heroin or methamphetamine. ${ }^{(15)}$ Alarmingly, the number of new youth abusers under the age of 20 also increased (by 47\%; from 155 in 2010 to 228 in 2011). Since the mid-2000s, several measures have been put in place at a national level to curb the problem of substance abuse in Singapore. These measures include the introduction of Clinical Practice Guidelines for the management of opiate dependence, the creation of a Central Drug Prescribing Registry for the monitoring of prescription patterns, and the development of the Subutex Voluntary Rehabilitation Programme in 2006 to assist substance users dependent on buprenorphine. Significant changes in the law were also made, including long-term imprisonment of recalcitrant users and stricter sentencing for offences related to possession and trafficking. ${ }^{(16)}$

The Institute of Mental Health (IMH) is the only tertiary psychiatric care institution in Singapore that treats a range of psychiatric disorders. The Community Addictions Management Programme was set up within IMH in 2001 to provide in- and outpatient treatment for patients with behavioural and substance addictions. In recognition of the increasing needs of this subgroup of patients, the National Addictions Management Service (NAMS) was established in 2009 with the launch of a new specialist clinic. Over the years, NAMS has also extended its services to IMH's satellite clinics and improved community support through public awareness events and training programmes on how to

${ }^{1}$ Department of Psychological Medicine, Tan Tock Seng Hospital, ${ }^{2}$ National Addictions Management Service, Institute of Mental Health, ${ }^{3}$ Department of Medicine (Psychiatry), Ng Teng Fong General Hospital, ${ }^{4}$ Program in Health Services and Systems Research, Program in Neuroscience and Behavioral Disorders, Duke-NUS Graduate Medical School, Singapore Correspondence: DrRochelle Melina Kinson, Associate Consultant, Department of Psychological Medicine, Tan Tock Seng Hospital, 11 Jalan Tan Tock Seng, Singapore 308433. rochelle_kinson@ttsh.com.sg 
recognise the signs of addiction and manage addictions. These training programmes are specially catered to school counsellors and grassroots organisations.

To date, only one study has looked at the prevalence rates of blood transmitted infections (BTIs), namely hepatitis B, hepatitis C and HIV infections, in local substance abusers. ${ }^{(17)}$ Winslow et al examined a sample of injecting buprenorphine users in an outpatient setting between 2005-2006 and found that the rates of $\mathrm{HBV}, \mathrm{HCV}$ and HIV infections were $8.5 \%, 42.5 \%$ and $0 \%$, respectively; ${ }^{(17)}$ these rates were higher than those of the general population in Singapore. ${ }^{(18-20)}$

Given the increasing number of drug arrests and the change in substance use profiles, ${ }^{(21)}$ there is a need to establish the current rates of BTIs within a broader substance-abusing population. Previous international studies have explored the risk factors for $\mathrm{BTI}$, including age, ${ }^{(22-24)}$ number of years injecting drugs, ${ }^{(22,23,25-27)}$ needle-sharing, ${ }^{(23,26-28)}$ type of drug injected, ${ }^{(25)}$ other sociodemographic factors and risk practices. ${ }^{(22-28)}$ Although a range of other BTIs are known to be associated with IV substance use (e.g. Cytomegalovirus and bacterial infections), HBV, HCV and HIV infections are those that are commonly tested for in the local setting, and as such, they were the main focus of the present study. The objective of the present study was to estimate the prevalence of BTIs and identify the factors associated with BTIs among patients undergoing inpatient detoxification and rehabilitation at NAMS for substance use disorders.

\section{METHODS}

The present study used a single site, retrospective case note analysis design. The medical records of all inpatients admitted to the NAMS inpatient programme in Singapore from 1 June 2009 to 31 May 2010 were reviewed. These patients were diagnosed with a current or lifetime history of substance use disorder by the treating team, based on the Diagnostic and Statistical Manual (DSM-IV-TR). ${ }^{(29)}$ Patients who were diagnosed with behavioural addiction and/or alcohol use, and did not have a history of drug use, were excluded from the present study because this subgroup of patients are not routinely tested for BTIs.

The study was approved by the local Institutional Review Board (Ref no.: 2010 / 00630) and informed consent was waived. Essential demographic details and information regarding the patients' substance use were collected. Medical records were retrospectively reviewed to identify patients who had blood tests that were positive for HBV, HCV or HIV infections. If the patients did not have any record of tests for BTIs, they were excluded from the analysis.

All statistical analyses were performed using the Predictive Analytics SoftWare version 18 for Windows (SPSS Inc, Chicago, IL, USA). We compared the demographics and substance use characteristics of patients who were BTI-positive with those who were BTI-negative. Student's $t$-test was used to analyse continuous variables, and chi-square test was used for categorical variables. Valid percentages were calculated based on available (non-missing) data. The association between the aforementioned variables with binary BTI status was also investigated using logistic regression analysis (i.e. age, total substances used, needle-sharing and lifetime IV drug use were the independent variables, with BTI as the dependent variable).

\section{RESULTS}

The medical records of all patients admitted to the NAMS inpatient programme in Singapore from 1 June 2009 to 31 May 2010 were examined. From a total of 263 admission records, 80 were repeat visits within the study period and were therefore excluded from the analysis. For the patients with more than one admission within the study period, the most recent admission was utilised in the data collection. Of the remaining 183 records, 13 records did not have documentation of the BTI tests performed. The final 170 NAMS inpatients who met the inclusion criteria were predominantly male and Chinese, with a mean age of 43.1 years. More than half of the 170 patients had at least a secondary school education, $41.2 \%$ were employed and $40.6 \%$ were married (Table I).

Only a small proportion of patients (8.2\%) were diagnosed with psychiatric comorbid disorders, of which most were mood disorders (30.4\%), followed by anxiety disorders, psychotic disorders $(8.7 \%$ each) and other Axis II disorders (13.0\%). No significant difference in the comorbidity rates was found between patients who tested positive for BTIs and those who tested negative for BTIs $(p=0.59)$.

Most (86.5\%) of the patients were opioid dependent. Sedative/ hypnotic/anxiolytic use disorder and polysubstance use disorder were the primary diagnoses in $8.2 \%$ and $2.9 \%$ of the patients, respectively. The mean number of substances used by the patients in their lifetime was four. Heroin was the reported drug of initiation in $54.7 \%$ of the patients, followed by cannabis (17.1\%). A small proportion of patients $(11.5 \%)$ shared needles.

Of the 170 patients, $70(41.2 \%)$ were found to be positive for either HCV, HBV or HIV (i.e. BTI-positive patients). The prevalence of $\mathrm{HCV}, \mathrm{HBV}$ and $\mathrm{HIV}$ in the patients who were BTIpositive were $95.7 \%, 9.0 \%$ and $0 \%$, respectively. Only current IV drug use $\left(\chi^{2}[1,169]=16.6, p<0.001\right)$ and lifetime IV drug use $\left(\chi^{2}[1,170]=13.89, p<0.001\right)$ were significantly different between the BTI-positive and BTI-negative patients. No other characteristics were found to be significantly different between the BTI-positive and BTI-negative patients.

We also considered the possibility of a window period of seroconversion, which could affect BTI status. However, among the 80 repeat admissions (57 patients), there were no changes in the BTI status when initial BTI tests results were compared with the most recent test results (which were the results that were utilised in the data collection and analysis).

The logistic regression analysis model (with age, total substances used, needle-sharing, and lifetime IV drug use as independent variables, and BTI as the dependent variable) found that lifetime IV drug use was the only significant predictor of BTI (odds ratio 4.3, 95\% confidence interval 1.7-10.8, $\mathrm{p}<0.01$ ). This suggests that patients with lifetime IV drug use were at least four times more likely to contract a BTI. The model was significant (Nagelkerke's $R^{2}=0.123, \chi^{2}[4,131]=12.3, p<0.05$ ) and accounted for $12.3 \%$ of the variance. 
Table I. Demographics and substance use profiles of the inpatients $(n=170)$.

\begin{tabular}{|c|c|c|c|c|c|}
\hline \multirow[t]{2}{*}{ Parameter } & \multicolumn{3}{|c|}{ No. (\%) } & \multirow[t]{2}{*}{$t / \chi^{2}$} & \multirow[t]{2}{*}{ p-value } \\
\hline & All & BTI (+) & BTI (-) & & \\
\hline $\mathrm{Age}^{+}$ & $43.1 \pm 8.9$ & $43.3 \pm 8.8$ & $43.0 \pm 9.1$ & 0.22 & 0.83 \\
\hline Male gender & $150(88.2)$ & $62(88.6)$ & $88(88.0)$ & 0.01 & 0.91 \\
\hline Race & & & & 6.71 & 0.08 \\
\hline Chinese & $99(58.2)$ & $33(47.1)$ & $66(66.0)$ & & \\
\hline Indian & $14(8.2)$ & $6(8.6)$ & $8(8.0)$ & & \\
\hline Others & $5(2.9)$ & $3(4.3)$ & $2(2.0)$ & & \\
\hline Secondary education and above* & $100(58.8)$ & $38(57.6)$ & $62(63.3)$ & 0.54 & 0.46 \\
\hline Employed* & $70(41.2)$ & $27(40.9)$ & $43(43.4)$ & 0.1 & 0.75 \\
\hline Married* & $69(40.6)$ & $27(39.7)$ & $42(43.3)$ & 0.21 & 0.65 \\
\hline Living alone* & $22(13.2)$ & $10(14.7)$ & $12(12.1)$ & 0.24 & 0.63 \\
\hline Primary diagnosis & & & & 5.21 & 0.27 \\
\hline Opioid use disorder & $147(86.5)$ & $61(87.1)$ & $86(86.0)$ & & \\
\hline Sedative/hypnotic/anxiolytic use disorder & $14(8.2)$ & $8(11.4)$ & $6(6.0)$ & & \\
\hline Polysubstance disorder & $5(2.9)$ & $1(1.4)$ & $4(4.0)$ & & \\
\hline Other substance ${ }^{\ddagger}$ use disorders & $4(2.4)$ & $0(0)$ & $4(4.0)$ & & \\
\hline Psychiatric comorbidity* & & & & 3.73 & 0.59 \\
\hline \multicolumn{6}{|l|}{ Axis I } \\
\hline Mood disorder & $7(30.4)$ & $5(41.7)$ & $2(18.2)$ & & \\
\hline Anxiety disorder & $2(8.7)$ & $1(8.3)$ & $1(9.1)$ & & \\
\hline Psychotic disorder & $2(8.7)$ & $0(0)$ & $2(18.2)$ & & \\
\hline \multicolumn{6}{|l|}{ Axis II } \\
\hline Personality disorder & $3(13.0)$ & $1(8.3)$ & $2(18.2)$ & & \\
\hline
\end{tabular}

*Data is calculated as valid percentages due to missing cases. tData presented as mean \pm standard deviation. ${ }^{*} \mid$ ncludes alcohol and hallucinogens.

$\mathrm{BTI}(+)$ : blood transmitted infection-positive; BTI(-): blood transmitted infection-negative; IV: intravenous

\section{DISCUSSION}

The main findings of the present study were: (a) $41.2 \%$ of our study cohort had BTIs (3.7\% HBV, 39.6\% HCV and 0\% HIV); and (b) the single significant predictor of BTI was lifetime IV drug use. Comorbid psychiatric illness was exceptionally low at $8.2 \%$, and only $11.5 \%$ of the patients admitted to sharing needles/injecting paraphernalia. The prevalence of BTIs was significantly lower than that reported among most drug-using populations in international data. ${ }^{(4-12)}$ Although the complete absence of HIV in the present study is encouraging, this finding must be viewed cautiously.

Patients with lifetime IV drug use were found to be more than four times more likely to have a BTI-positive status, and the prevalence of BTIs in our study cohort was significantly higher than that of the local population. ${ }^{(18-20)}$ Although causality cannot be inferred given the retrospective nature of the present study, the observed association between BTI status and lifetime IV drug use is not surprising in light of the current literature. ${ }^{(30-32)}$ This finding provides a potential avenue for future research and intervention.

As our study cohort consisted of help-seekers who received inpatient treatment, they may have had a higher severity of drug dependence as compared to patients treated in an outpatient setting. Therefore, the prevalence of BTI may be an overestimate.
However, incarcerated drug users would not have been captured in the present study and these users would constitute a potentially higher risk group.

Only a small proportion of our study cohort reported needle-sharing, and this is not significantly associated with a BTI-positive status. It is postulated that, while formal needleexchange programmes are not in operation in Singapore, needles are relatively easy to obtain from small medicinal shops, thus explaining the low rates of needle-sharing. It is also possible that the patients in the present study under-reported the sharing of injecting equipment, given the stigma attached to injecting drug users locally. It is important to note that needles and syringes are not the only source of parenteral transmission of BTIs; sharing of cookers, cotton and water may also contribute to the parenteral transmission of BTIs, and these types of sharing are difficult to quantify. Sexual contact is another possible route of disease transmission, which was not explored in the present study.

International epidemiology studies, such as the United Kingdom's National Household Survey, revealed that approximately $45 \%$ of drug-dependent individuals met the criteria for at least one comorbid psychiatric disorder, and about $12 \%$ met the criteria for two or more disorders. ${ }^{(33)}$ In Singapore, however, the rate of comorbid psychiatric disorders is exceptionally low, as demonstrated in the present study. While positive cultural 
and religious backgrounds, as well as better social support, may offer some protection against psychiatric disorders, it is possible that drug users in Singapore are less likely to report symptoms of psychiatric disorders because of the perceived stigma. Further research could be conducted to delineate the reasons for the discrepancy in the rates of psychiatric disorders.

Prevention work in the community is pertinent since the literature suggests that only a small proportion of substance users has sufficient knowledge on BTIs and actively seek treatment. ${ }^{(34,35)}$ Educating substance users on the risks of BTI at every point of contact with social services or treatment centres is paramount. Although vaccines are available for the prevention of $\mathrm{HBV}$, the rate of HBV infection among injecting drug users remains high. ${ }^{(36)}$ This could be due to a lack of knowledge on existing treatments and/or financial constraints. It is worrisome that, in the present study, although half of the patients with current IV drug use had $\mathrm{HCV}$ (which is potentially treatable), these patients may not receive the proper medical attention.

Additional screening and treatment methods should be in place to improve the rates of BTI detection and treatment. For example, addiction clinics could establish standardised screenings for BTIs that are followed by referrals to gastroenterologists if BTI is detected, and rigorous monitoring and social welfare support systems could be set up to ensure compliance to treatment. The 2012 World Health Organization guidance report on the prevention of hepatitis in injecting drug users listed five evidence-based recommendations, which included offering HBV vaccination packages and peer interventions. ${ }^{(37)}$ These are areas for empirical research in the Singaporean context in order to reduce harm to drug users and the wider community.

The present study contributes to the existing limited baseline data regarding the health-related risks of substance abuse and the factors associated with these risks. We did not rely on selfreport measures for BTI status. Instead, the blood test results of the patients were verified through the review of inpatient and outpatient medical records, as well as electronic records. However, the present study was not without limitations. Although BTI screening is offered to all NAMS patients, not all patients gave consent as this screening was not a mandatory part of treatment $(10 \%$ of the 170 patients did not have a complete BTI profile). Given the retrospective design of the study, data collection was limited to the extent of documentation in the medical records. This resulted in notable gaps, such as those due to undocumented sexual history and incomplete demographic and clinical information. The findings may not be generalisable to a wide range of substance users who are seeking help, including those receiving outpatient care and those in prisons or drug rehabilitation centres.

In conclusion, the present study highlights that the prevalence of BTIs among substance users receiving treatment is lower in Singapore than in other countries. Nevertheless, BTIs remain a significant health-related problem. Therefore, prevention and early detection via screenings during any point of contact with the health service is important. It is our hope that the findings of the present study will contribute to health planning policies in
Singapore, as well as provide a platform for future research on this vulnerable population.

\section{REFERENCES}

1. World Health Organization. Hepatitis C Fact sheet $N^{\circ} 164$ [online]. Available at: http://www.who.int/mediacentre/factsheets/fs164/en/. Accessed December 13, 2012.

2. World Health Organization. Hepatitis B Fact sheet $N^{\circ} 204$ [online]. Available at: http://www.who.int/mediacentre/factsheets/fs204/en/. Accessed December 13, 2012.

3. World Health Organization. HIV/AIDS Fact sheet $\mathrm{N}^{\circ} 360$ [online]. Available at: http://www.who.int/mediacentre/factsheets/fs360/en/. Accessed December 13, 2012.

4. United Nations Office on Drugs and Crime. World Drug Report 2011. Available at: http://www.unodc.org/documents/data-and-analysis/ WDR2011/World_Drug_Report_2011_ebook.pdf. Accessed December 13, 2012.

5. Diaz T, Des Jarlais DC, Vlahov D, et al. Factors associated with prevalent hepatitis C: differences among young adult injection drug users in lower and upper Manhattan, New York City. Am J Public Health 2001; 91:23-30.

6. Garfein RS, Doherty MC, Monterroso ER, et al. Prevalence and incidence of hepatitis $C$ virus infection among young adult injection drug users. J Acquir Immune Defic Syndr Hum Retrovirol 1998; 18 Suppl 1:S11-9.

7. Garfein RS, Vlahov D, Galai N, Doherty MC, Nelson KE. Viral infections in short-term injection drug users: the prevalence of the hepatitis $\mathrm{C}$, hepatitis B, human immunodeficiency, and human T-lymphotropic viruses. Am J Public Health 1996; 86:655-61.

8. Hahn JA, Page-Shafer K, Lum PJ, Ochoa K, Moss AR. Hepatitis C virus infection and needle exchange use among young injection drug users in San Francisco. Hepatology 2001; 34:180-7.

9. Nelson PK, Mathers BM, Cowie B, et al. Global epidemiology of hepatitis B and hepatitis $C$ in people who inject drugs: results of systematic reviews. Lancet $2011 ; 378: 571-83$.

10. Thorpe LE, Ouellet LJ, Hershow R, et al. Risk of hepatitis C virus infection among young adult injection drug users who share injection equipment. Am J Epidemiol 2002; 155:645-53.

11. Villano SA, Vlahov D, Nelson $K E$, et al. Incidence and risk factors for hepatitis $\mathrm{C}$ among injection drug users in Baltimore, Maryland. J Clin Microbiol 1997; 35:3274-7.

12. Zeldis JB, Jain S, Kuramoto IK, et al. Seroepidemiology of viral infections among intravenous drug users in northern California. West J Med 1992; 156:30-5.

13. Mathers BM, Degenhardt L, Ali H, et al.; 2009 Reference Group to the UN on HIV and Injecting Drug Use. HIV prevention, treatment, and care services for people who inject drugs: a systematic review of global, regional, and national coverage. Lancet 2010; 375:1014-28.

14. Central Narcotics Bureau, Singapore. Drug situation report 2011 [online]. Available at: http://www.cnb.gov.sg/drugsituationreport/ drugsituationreport2011.aspx. Accessed December 13, 2012.

15. Central Narcotics Bureau, Singapore. Drug and inhalant situation report Jan-Jun 2012 [online]. Available at: http://www.cnb.gov.sg/Libraries/CNB_ MediaLibrary_Files/CNB_Drug_Situation_Report_Jan-Jun_2012_final.sflb. ashx. Accessed December 13, 2012.

16. Ministry of Home Affairs, Singapore. Tougher action against subutex abuse [online]. Available at: http://www.mha.gov.sg/news_details. aspx?nid=MzI5-\%2Fs8TkZ2OVYM\%3D. Accessed December 13, 2012.

17. Winslow M, Subramaniam M, Ng W, et al. Seroprevalence of hepatitis C in intravenous opioid users presenting in the early phase of injecting drug use in Singapore. Singapore Med J 2007; 48:504-8.

18. Hong WW, Ang LW, Cutter JL, et al. Changing seroprevalence of hepatitis B virus markers of adults in Singapore. Ann Acad Med Singapore 2010; 39:591-8.

19. Ministry of Health, Singapore. Seroprevalence of human immunodeficiency virus (HIV) among sentinel surveillance populations in Singapore, 19892008. Epidemiol News Bull 2009; 35:63-8.

20. Ong SC, Lim SG, Li SC. How big is the financial burden of hepatitis B to society? A cost-of-illness study of hepatitis B infection in Singapore. J Viral Hepat 2009; 16:53-63.

21. Peh AL, Lim YC, Winslow RM. Addiction in Singapore: changing patterns and evolving challenges. Singapore Med J 2012; 53:435-7.

22. Freeman RC, Rodriguez GM, French JF. Seroprevalence and risk factors associated with HTLV-I/II infection in injection drug users in northern New Jersey. J Addict Dis 1995; 14:51-66. 
23. Miller M, Mella I, Moi H, Eskild A. HIV and hepatitis $C$ virus risk in new and longer-term injecting drug users in Oslo, Norway. J Acquir Immune Defic Syndr 2003; 33:373-9.

24. Roy E, Haley N, Leclerc $P$, et al. Risk factors for hepatitis $C$ virus infection among street youths. CMAJ 2001; 165:557-60.

25. Crofts N, Jolley D, Kaldor J, van Beek I, Wodak A. Epidemiology of hepatitis $\mathrm{C}$ virus infection among injecting drug users in Australia. J Epidemiol Community Health 1997; 51:692-7.

26. Miller CL, Johnston C, Spittal PM, et al. Opportunities for prevention: hepatitis $\mathrm{C}$ prevalence and incidence in a cohort of young injection drug users. Hepatology 2002; 36:737-42.

27. Roy E, Alary M, Morissette C, et al.; SurvUDI Working Group. High hepatitis $C$ virus prevalence and incidence among Canadian intravenous drug users. Int J STD AIDS 2007; 18:23-7.

28. Nokhodian Z, Meshkati M, Adibi $\mathrm{P}$, et al. Hepatitis $\mathrm{C}$ among Intravenous Drug Usersin Isfahan, Iran: a Study of Seroprevalence and Risk Factors. Int J Prev Med 2012; 3(Suppl 1):S131-8.

29. American Psychiatric Association. Diagnostic and statistical manual-text revision (DSM-IV-TR). American Psychiatric Association, 2000.

30. National Institute of Health. Management of Hepatitis C. In: NIH Consensus Development Program [online]. Available at: http://consensus.nih gov/1997 / 1997HepatitisC105html.htm. Accessed December 13, 2012.

31. Stoové MA, Fry CL, Lintzeris N. Quantifying hepatitis C transmission risk using a new weighted scoring system for the Blood-Borne Virus Transmission Risk Assessment Questionnaire (BBV-TRAQ): applications for community-based HCV surveillance, education and prevention. Harm Reduct J 2008; 5:12.

32. Bao YP, Liu ZM. Systematic review of HIV and HCV infection among drug users in China. Int J STD AIDS 2009; 20:399-405.

33. Farrell $M$, Howes $S$, Bebbington $P$, et al. Nicotine, alcohol and drug dependence and psychiatric comorbidity. Results of a national household survey. Br J Psychiatry 2001; 179:432-7.

34. Doab A, Treloar C, Dore G). Knowledge and attitudes about treatment for hepatitis $C$ virus infection and barriers to treatment among current injection drug users in Australia. Clin Infect Dis 2005; 40 Suppl 5:S313-20.

35. Stein MD, Maksad J, Clarke J. Hepatitis C disease among injection drug users: knowledge, perceived risk and willingness to receive treatment. Drug Alcohol Depend 2001; 61:211-5.

36. Kuo I, Sherman SG, Thomas DL, Strathdee SA. Hepatitis B virus infection and vaccination among young injection and non-injection drug users: missed opportunities to prevent infection. Drug Alcohol Depend 2004; 73:69-78.

37. World Health Organization. Guidance on prevention of viral hepatitis B and $\mathrm{C}$ among people who inject drugs [online]. Available at: http://www. who.int/hiv/pub/guidelines/hepatitis/en/index.html. Accessed December 13,2012 